\title{
Bees in the miombo Buzzing toward the Millennium Development Goals
}

\author{
Can beekeeping contribute sustainably to the Millennium Development Goals in \\ the miombo woodlands of southern Africa?
}

\section{Background}

Beekeeping has a long history in the miombo woodlands. Since pre-colonial times woodland bee products have been traded locally in urban markets and exported (Kadale Consultants 2005; MickelsKokwe 2006; Match Maker Associates 2007). The importance attributed to the sector by national governments in the region is demonstrated by the implementation of national beekeeping policies such as that developed in Tanzania in 1998 and the one currently under development in Zambia. Beekeeping is mentioned as a viable activity in joint forest management schemes in several forest policies and beekeeping extension is one of the key responsibilities of forestry departments across the region. Poverty levels in the region are amongst

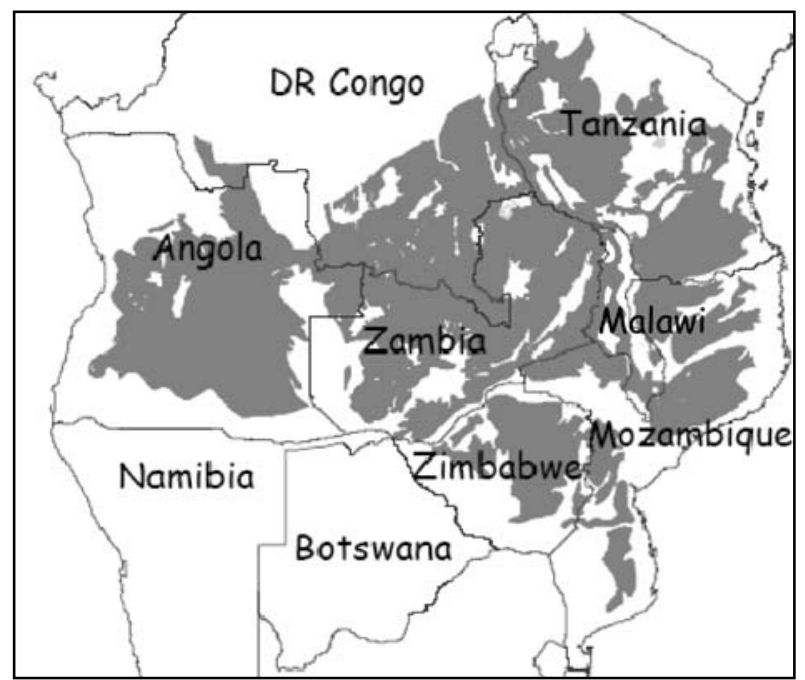

Figure 1. The distribution of miombo woodlands Source: Campbell et al. 2008 the highest in the world and rapid deforestation threatens the natural resource base on which the poor depend for much of their livelihood (Table 1). For decades, beekeeping has been promoted in both government and donor-funded development projects aimed at contributing to rural livelihood improvement and sustainable forest management. Thousands of small-scale farmers have been trained

\section{Box 1. Beekeeping in the miombo}

Miombo describes African woodlands that are dominated by tree species such as Brachystegia, Julbernardia and Isoberlinia spp. These woodlands cover approximately 2.7 million $\mathrm{km}^{2}$, stretching across Angola, Democratic Republic of Congo, Malawi, Mozambique, Tanzania, Zambia and Zimbabwe (Figure 1). Within the region, beekeeping is most popular in locations that have abundant miombo woodland cover such as Zambia's Northwestern Province, Tanzania's Tabora region, northern Angola and Mulanje District in Malawi. It is spreading quickly to other areas as people are lured by the success of 'liquid gold'. In 1990, an estimated 40 million rural people inhabited areas covered by miombo woodland. These woodlands are particularly suitable for beekeeping, because they provide excellent bee forage, and the bark of several species is an abundant resource for making traditional bark hives. In most areas, beekeepers are able to harvest twice a year, depending on the dominant tree species and their flowering patterns (Frost 1993; Kadale Consultants 2005; Mickels-Kokwe 2006; Match Maker Associates 2007). 
Table 1. Characteristics of countries with large areas of miombo woodland

\begin{tabular}{lrrrrrr}
\hline & Angola & Malawi & Mozambique & Tanzania & Zambia & Zimbabwe \\
\hline $\begin{array}{l}\text { Population living on PPP less than US \$2 a } \\
\text { day 1990-2005 (\%) }\end{array}$ & No data & 62.9 & 74.1 & 89.9 & 87.2 & 83.0 \\
$\begin{array}{l}\text { Human Development Index 2007/2008 } \\
\text { (rank out of 177) }\end{array}$ & 162 & 164 & 172 & 159 & 165 & 151 \\
$\begin{array}{l}\text { Rural population in 2007/2008 (\%) } \\
\text { Total forest cover (x1000 ha) }\end{array}$ & 49104 & 3402 & 19262 & 35257 & 42453 & 17540 \\
$\begin{array}{l}\text { Annual deforestation 2000-2005 } \\
\text { (x 1000 ha) }\end{array}$ & 125 & 33 & 50 & 412 & 445 & 313 \\
\hline
\end{tabular}

Sources: FAO 2007 and UNDP 2007

in beekeeping skills and millions of US dollars' worth of beekeeping equipment has been distributed.

This raises some important questions:

- What types of benefits does the beekeeping sector provide and who benefits?

- Can these benefits contribute to achieving the Millennium Development Goals?

- How can the sector be supported to help maximise these benefits and address the existing constraints?

\section{Benefits of the beekeeping sector}

Most beekeepers are also small-scale farmers, for whom beekeeping is part of a diverse livelihood portfolio. Traditional beekeeping systems require little cash investment and can be easily integrated with other seasonal rural activities. Beekeeping tends to enhance agricultural productivity and hence food production through increased pollination.

An estimated $90 \%$ of the beekeepers in the region make hives from bark or logs, and suspend them high in trees some distance from the homestead (Nel et al. 2000; Kadale Consultants 2005; Mickels-Kokwe 2006; Match Maker Associates 2007). Because of this method, beekeeping has been predominantly a male-dominated activity. However, the introduction of modern technologies has allowed more women to get involved (Shackleton et al. 2008). Both poor and wealthy households keep bees, because of the low costs, the ease of entry into beekeeping and the potentially high returns (Husselman 2008).
This money comes at a critical time of the year (i.e. November and June) when farmers need cash to purchase seeds and fertilisers. Other beekeepers use the income to send their children to school, to buy household goods or to invest in small businesses.

In areas where only a few households are involved in beekeeping, honey is sold predominantly within the community or in nearby urban areas, either for consumption or for processing into locally brewed honey beer (Mickels-Kokwe 2006; Husselman 2008). When sufficient volumes of honey are produced, urban traders, intermediaries and company agents travel to the communities to purchase it. Because much of the honey trade is not captured in official statistics, the total number of people involved and the volumes traded are unknown. In Mozambique, an estimated 30000 unregistered small and medium

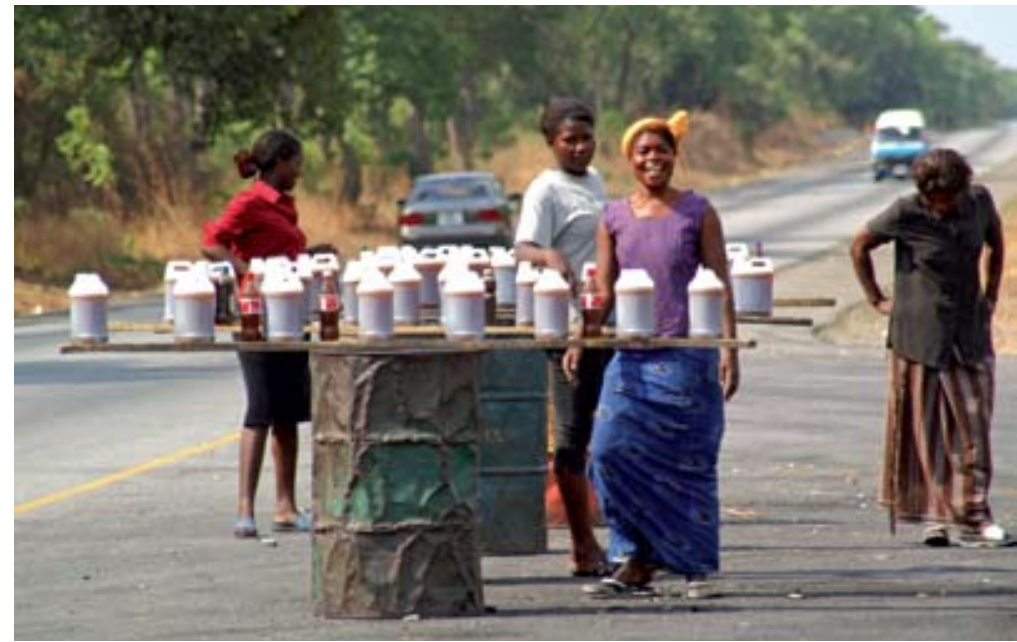

Zambian women selling locally produced honey at roadside stalls (Photo by Fiona Paumgarten) 
enterprises are involved in honey production and trading, compared to 4000 registered ones (Nhancale et al. 2009).

In Mwinilunga and Solwezi, two towns in Zambia, an estimated 50 and 130 beer brewers, respectively, are active during the honey season. More than $75 \%$ of these brewers are women, many of them uneducated and single or widowed. Similarly, a survey of the market traders selling honey in Lusaka revealed that the majority are women (Funda 2009).

\section{Beekeeping and the Millennium Development Goals}

In September 2000, leaders from around the world agreed to address 8 Millennium Development Goals (MDGs), aiming to reduce extreme poverty by 2015 . Beekeeping could contribute to achieving MDG 1, end poverty and hunger, and MDG 7, environmental sustainability.

\section{MDG 1: End poverty and hunger}

Recent studies indicate that the beekeeping sector has generally not provided a pathway out of poverty (Husselman and Paumgarten 2009). However, in areas where there are little or no alternative sources of cash income, beekeeping does play a vital role in preventing households from sinking deeper into poverty. In Mwinilunga district, one of Zambia's beekeeping hotspots, half of the rural households keep bees. In this remote area, the US\$140 that households earn on average per year from selling honey is their main source of cash income (Husselman and Paumgarten 2009).

But there is scope for improvement. Current production is far below potential: some beekeepers have been able to harvest more than $500 \mathrm{~kg}$ of honey per season, earning up to US\$1000. Research indicates that poor management is a key factor determining low productivity (Husselman and Funda 2009). Often people are trained in basic beekeeping skills, but lack further support in hive management and marketing. Additionally, many beekeepers lack the necessary business skills and financial support to invest sufficiently in their beekeeping activities and maximise the returns from their efforts, for example through value addition (Nel et al. 2000; Kadale Consultants 2005; Match Maker Associates 2007; Paumgarten and Hara 2009).

Further along the value chain - activities from resource to market - intermediaries, processing companies, beer brewers and traders are hampered by lack of information about where to locate beekeepers, poor infrastructure, lack of affordable and durable packaging materials, and few opportunities for affordable loans. As a result, there is usually little competition amongst buyers in the rural areas and beekeepers are not in a position to negotiate a fair price. On the other hand, in urban areas, the price of honey is high because of the high costs incurred along the value chain, making it affordable only to the relatively small middle and upper economic classes. Nonetheless, in most countries in the region, the domestic market is far from saturated (Kadale Consultants 2005; MickelsKokwe 2006; Match Maker Associates 2007) and there is potential for growth especially if consumer prices are reduced. Removing trade barriers through organisations such as the Southern African Development Community (SADC) and the Common Market for Eastern and Southern Africa (COMESA) would create opportunities for more regional trade. The presence of vast, unpolluted woodlands enables honey production for niche organic markets. In addition, increased organisation of producers into associations and cooperatives opens fair trade marketing opportunities.

Beekeeping has the potential to contribute more significantly to poverty alleviation, but returns to labour and other investments need to increase through improved productivity and higher prices for producers.

\section{MDG 7: Environmental sustainability}

Beekeeping is, in principle, not destructive to the environment. Although excessive harvesting of bark from Brachystegia or Julbernadia trees for hive construction is mentioned as a cause for killing these trees in some areas, bark use for 'doors' at 
the end of each hive is of greater concern. This can have a high impact on Parinari curatellifolia trees, a multiple-use, ritually important species that is scattered throughout the miombo woodland. Nonetheless, beekeeping can be combined with sustainable forest management and it is therefore an authorised activity in some protected areas (Kadale Consultants 2005; Mickels-Kokwe 2006; Match Maker Associates 2007). However, most beekeepers are struggling to make ends meet financially and continue to also depend on charcoal production or shifting cultivation to supplement household income. As a result, significant positive impacts on forest management have not yet been recorded. Many individuals have managed to significantly increase their household income by selling bee products and therefore are inclined to see the value of sustainable forest management. However, only beekeepers with access to alternative technologies have actually been able to reduce their cutting of trees. Other beekeepers acknowledge that healthy trees are necessary for sustainable honey production, but admit they still need to cut trees to make hives.

\section{What needs to be done?}

The important contribution of the beekeeping sector to the livelihoods of hundreds of thousands of families in the miombo region is clear. Based on CIFOR research in Zambia and that of other researchers in neighbouring countries, some recommendations to strengthen the sector and achieve MDGs 1 and 7 within the miombo region can be made.

\section{Develop and disseminate production, processing and value-adding technologies and management skills}

- Invest in research to develop appropriate beekeeping and processing systems. Tailormade technologies and related management practices have proven to be the most successful. An excellent example is the Kenyan top bar hive made from mud bricks, which has enabled
Zambia's Kapiri district to become a popular source of honey in less than a decade.

- Design long-term extension programmes to match the needs and experiences of beneficiaries. In particular, when introducing a new technology or training inexperienced beekeepers, technical backstopping is needed for at least two years after the intervention.

- Stimulate local production and trade of beekeeping equipment. To reduce costs and create additional jobs, empower all the actors in the value chain, including carpenters and tailors. Furthermore, avoid distributing equipment for free as beekeepers need to be aware of the market price of equipment, to enable business planning and future reinvestments.

\section{Improve economic and marketing support}

- Promote the diversification of markets, by conducting adequate market research and including marketing and business modules in extension programmes. It is much easier and often more profitable for beekeepers and processing companies to target domestic and regional markets, instead of exporting to Europe. It is important not to depend solely on one buyer.

- Encourage diversification of bee-derived products. Beeswax and propolis have very high market values and could provide additional incomes for beekeepers. Value addition can be done, for example, by labelling the botanical source or geographic origin of the honey; processing into new products such as cosmetics, food stuffs or medicines; improved packaging; and targeting new consumers. Market research and product promotion is essential; specialised production should not be encouraged if there is no market available.

- Build on or develop national and regional standards and certification schemes for bee-derived products. This requires a wellfunctioning internal monitoring system and building the capacity of the local actors to manage the necessary logistics. Building 
international confidence that actors adhere to these standards will facilitate exports and improve the reputation of honey produced in the region.

- Disseminate information on new production systems and different markets. For example, since 2008 Zambian beekeepers are able to access real-time prices offered by different honey processing companies, as well as their contact details, through a text messaging (short message service) system. This strengthens their ability to negotiate prices and contact favourable buyers.

- Recognise informal and part-time actors. Large volumes of honey are bought and sold informally as comb or liquid honey, or processed into honey beer. These invisible traders need access to appropriate processing technologies, financial capital and marketing information, without being obliged to enter the formal sector. A full-time commitment to this sector may not be affordable for the poorest of the poor who rely on diverse income activities.

- Promote and strengthen collective action amongst different stakeholder groups. Group production systems have not proved to be profitable but associations and cooperatives that support the marketing of members' beederived products have enabled beekeepers to increase incomes from honey sales. In particular, producer prices can be improved by bulking products, monitoring quality standards and ensuring regular supply.

- Facilitate access to microfinance. The poorest actors in the sector need credit facilities that have more flexible collateral conditions. In addition, capacity building is necessary to enable these actors to develop sound business plans and invest in their enterprises. In recent years, financial support given to several registered processing companies has improved the competition in the market; consequently, producer prices have increased as much as $75 \%$ in parts of Zambia and Malawi.

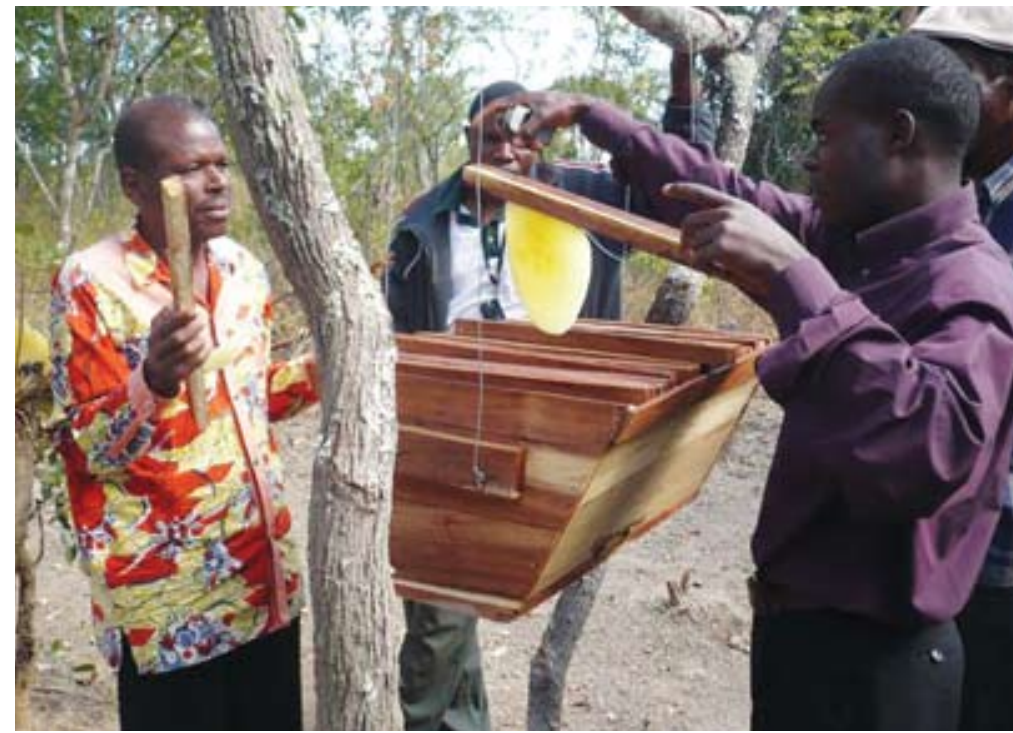

Zambian beekeepers examining one of the combs of a beehive (Photo by Fiona Paumgarten)

- Develop incentive-based systems for miombo management that link to international policies on carbon crediting and reducing emissions from deforestation and forest degradation. Such payment systems could improve low household incomes in beekeeping areas and are therefore worth testing at a pilot level.

\section{Improve the institutional and policy environment}

- Develop a national institution that is responsible for coordinating support to the sector. Increased coordination and networking facilities (stakeholder platforms, trade fairs, etc.) will not only help avoid duplication of efforts but will also improve collaboration amongst service providers. National institutions (e.g. the Zambian Honey Council) already exist, but increased cooperation of all stakeholders and more financial support are needed to enable these institutions to function effectively.

- Clarify roles and responsibilities of the different stakeholders and build legal frameworks to enforce and protect. For example, donor and public funds should not be used to buy up beederived products and thereby distort the market. 


\section{Concluding remarks}

It is unlikely that beekeeping alone can achieve the goals of poverty alleviation and environmental sustainability. Rather, it should be considered as part of the diversified livelihood portfolio that most households in the region employ. External factors such as agricultural, industrial and infrastructure development efforts will have a major impact on the success or failure of the beekeeping sector. In addition, general support to associations and cooperatives, capacity building of small and medium enterprises and access to education and improved healthcare will also have indirect positive impacts on the beekeeping sector. Thus, coordinated and intersectoral policies need to be developed and implemented.

\section{References}

Campbell, B.M., Angelsen, A., Cunningham, A., Katerere, Y., Sitoe, A. and Wunder, S. 2008 Miombo woodlands: opportunities and barriers to sustainable forest management. CIFOR, Bogor, Indonesia

Food and Agricultural Organization (FAO) 2007 State of the World's Forests. FAO, Rome.

Frost, P. 1993 The ecology of miombo woodlands. In: Campbell, B. (ed) The miombo in transition: woodlands and welfare in Africa. CIFOR, Bogor, Indonesia.

Funda, M. 2009 Honey and beeswax trade in urban areas. CIFOR report. http://www.cifor.cgiar.org/dryforest/_ ref/home/index.htm.

Husselman, M. 2008 Generating incomes from dry forest products: case studies from Mwinilunga, Kapiri and Chongwe districts, Zambia. Paper to the Sustainable Forest Management in Africa Symposium. Stellenbosch, South Africa, 3-7 November 2008.
Husselman, M. and Funda, M. 2009 Developing appropriate beekeeping technologies. CIFOR technical report. http://www.cifor.cgiar.org/dryforest/_ref/ home/index.htm.

Husselman, M. and Paumgarten, P. 2009 Alleviating poverty through beekeeping: lessons from Zambia. Paper to Apimondia, Montpellier, France, 15-20 September 2009.

Kadale Consultants 2005 Honey sub-sector initial report. Unpublished report. http://www.joyhecht.net/ mulanje/refs/Kadale-honey-subsector-2005.pdf [19 January 2010].

Match Maker Associates 2007 Honey and beeswax value chain analysis in Tanzania. Unpublished report. http:// www.marketaccesstz.org/scf/downloads.php [19 January 2010].

Mickels-Kokwe, G. 2006 Small-scale woodlands based enterprises with outstanding economic potential: the case study of honey in Zambia. CIFOR, Bogor, Indonesia.

Nel, E., lllgner, P.M., Wilkins, K. and Robertson, M.P. 2000 Rural self-reliance in Bondolfi, Zimbabwe: the role of beekeeping. Geographic Journal 166(1):26-34.

Nhancale, B., Mananze, S., Dista, N,, Nhantumbo, I. and Macqueen, D. 2009 Small and medium forest enterprises in Mozambique. Small and Medium Forest Enterprise Series 25. Centro Terra Viva and International Institute for Environment and Development, London.

Paumgarten, F. and Hara, R. 2009 Supporting collective action and poverty reduction in the Zambian honey sector. Paper to Apimondia. Montpellier, France, 15-20 November 2009.

Shackleton, S., Husselman, M., Zida M. and Kassa, H. 2008 Commercialisation of non-timber forest products. Where do women stand? Paper to the Sustainable Forest Management in Africa Symposium. Stellenbosch, South Africa, 3-7 November 2008.

United Nations Development Program (UNDP) 2007 Human Development Report 2007/2008. UNDP, New York.

This brief was prepared by Madeleen Husselman, Moira Moeliono and Fiona Paumgarten. The views expressed in this publication are those of the authors. We would like to thank Verina Ingram and Tony Cunningham for their valuable comments.

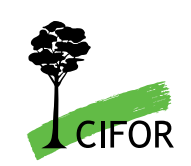

Center for International Forestry Research

CIFOR advances human wellbeing, environmental conservation and equity by conducting research to inform policies and practices that affect forests in developing countries. CIFOR is one of 15 centres within the Consultative Group on International Agricultural Research (CGIAR). CIFOR's headquarters are in Bogor, Indonesia. It also has offices in Asia, Africa and South America. 